\title{
A REVIEW ARTICLE ON: GREEN CHEMISTRY
}

Shraddha T Nemane, Vishweshwar M Dharashive, Suraj G Malpani, Nilesh N Shinde, Ayaj S Pathan.

Shivlingeshwar College of Pharmacy Almala Tq. Ausa Dist. Latur, Maharashtra India.

Article Info: Received 26 February 2020; Accepted 06 April 2020

DOI: https://doi.org/10.32553/jbpr.v9i2.736

Corresponding author: Shraddha T. Nemane

Conflict of interest statement: No conflict of interest

\section{Abstract}

The GC i.e Green chemistry revolution is the revolution that delivers a huge number of complications and challenges to those that are practicing chemistry in industries also in education and research. The start of green chemistry is taken into account as a response to the necessity to scale back the damage of environment by man made materials and therefore the process wont to produce them. Green chemistry could include anything from reducing waste to even removing waste in correct manner. All chemical waste should be disposed of within the absolute best manner without causing any damage to the environment and to the living beings. Green chemistry which is that the latest and one among the foremost researched topics now days has been in demand since 1990's. Majority of research in green chemistry aims to scale back the energy consumption required for the assembly of desired product whether it's going to be any drug, dyes and other chemical compounds. It aims to scale back or maybe eliminates the assembly of any harmful bi-products and maximizing the specified product without compromising with the environment.

Keywords: Enormous problems, disposing of waste, energy, Eliminates etc.

\section{Introduction}

The green chemistry is defined as a branch of science which utilizes a group of principles for the invention, design, development and implementation of chemical products and processes that reduce or eliminate the utilization and generation of hazardous substances. The approach in chemistry is protecting human health and environment and it represents a big departure from the normal methods previously used. before green chemistry the most aim was to attenuate exposure to chemicals, but green chemistry emphasizes the planning and creation of chemicals that aren't hazardous to people or the environment. it's been applied to a good range of commercial and commodity, including paints, dyes, fertilizers, pesticides, plastics, medicines, electronics, cleaning, energy generation, and water purification. Molecular structures of the chemicals decide their properties, which may be modified by changing the structures of the chemicals. Green chemistry addresses the varied hazards which will be caused by the chemicals, which include physical hazards (being explosive or flammable), toxicity (being carcinogenic or cancer causing, or lethal), or global hazards (climate change or stratospheric ozone depletion). Therefore under green chemistry the varied substances are often synthesized during a non hazardous way[1]. Within this, chemistry features a key role to play in maintaining and improving our quality of life, the competitiveness of the industry and therefore the natural environment. This role for chemistry isn't generally recognized by government or the general public. actually chemicals, chemistry and chemists are literally seen by many as causes of the issues .

\section{Green chemistry}

Green color is that the colour of chlorophyll and thus the colour of the dollar. Being a green series of years could also be a battleground of environmental activists, and becoming a green becoming a trend in product marketing. And for chemists it becomes imperative to be green in implementing the principles of green chemistry with some aspects of chemical sciences, in fundamental and applied research, production and education. [2].

\section{Definition of green chemistry}

According to the EPA definition, green chemistry is defined as a chemistry that designs chemical products and processes that are harmless to the environment, thus preventing the formation of pollution. Chemical products should be made in order that they're doing not remain within the environment at the top of their application which they are weakened into components that are harmless to the environment. Saving supported to all capable synthesis without the use of "exotic" i.e foreign reagents, with decreasing the required energy, 
and also replacing organic solvents with water are significant even at the laboratory level too, while in industrial scale possible millions of savings [3]. Green chemistry isn't a separate science, but a responsible interdisciplinary approach to science, supported chemical, ecological and social responsibility, which enables creativity and therefore the advancement of innovative research [4]. As a propulsive area of research, it tries to find and maintain a balance between the use of natural resources, economic growth and environmental conservation.

\section{Concept and ideas:-}

Green chemistry is that the utilization of a group of principles which will help reduce the utilization and generation of hazardous substances during the manufacture and application of chemical products. Green chemistry aims to protect the environment not only by cleaning up, but also by inventing new chemical processes that do not pollute. It is a rapidly developing and a crucial area within the chemical sciences.

The program of Green chemistry helps and supports the inventions or new things of more eco-friendly chemical processes which decrease or maybe eliminate the generation of harmful or hazardous substances.

This program works very closely related with the twelve principles of Green chemistry

\section{Basic principles of green chemistry [5]}

i. Prevention: it's to stop waste than to treat or pack up waste after it's been created.

ii. Atom Economy: its Synthetic methods should be designed to increase the incorporation of all materials used or utilise withinin the method into the last word product.

iii. Less Harmful and Hazardous Chemical Synthesis: Practicable synthetic methods should be designed for their uses and to generate the substances which possess very less or no toxicity to humans, their health and environment.

a. 4) Designing Safer Chemicals: These Chemical products should be designed to affect their desired typical functions while decreasing the toxicity.

iv. Safer Solvents and Auxiliary: the utilization of auxiliary substances should be made unnecessary wherever possible.

v. Design for Energy Efficiency: Energy requirements of chemical processes should be recognized for his or her environmental and at coldness and pressure.

vi. Use of Renewable Feedstock: A raw material or feedstock should be renewable rather than depleting whenever technically and practicable. vii. Reduce Derivatives: Unnecessary derivatization (use of blocking groups, protection, deprotection) should be avoided whenever possible.

viii. Catalysis: Some Catalytic reagents (selective) are chief stoichiometric reagents. [6]

ix. Design for Degradation: Chemical products should be designed in order that at the top of their function they break down into innocuous degradation products and don't continue the environment.

$x$. Real-time analysis for pollution prevention and safety of environment: Analytical methodologies need to be more developed to allow for real-time, in process monitoring and control before the formation of hazardous substances or harmful substances.

xi. Casual Safer Chemistry for Accidental prevention: Substances and therefore the sort of a substance utilized in a chemical change should be chosen to attenuate the potential for chemical accidents, with releases, explosions and fires.

a. These principles can inspire chemistry in the least levels: research, education and public perception. The first principle describes the essential idea of green chemistry in protecting the environment from pollution. The other principles are also focused on atom economy, toxicity, solvent and other media using consumption of energy, application of some raw materials from new renewable sources and degradation of chemical products to simple, nontoxic substances that safe for environment and friendly for the environment.[7]

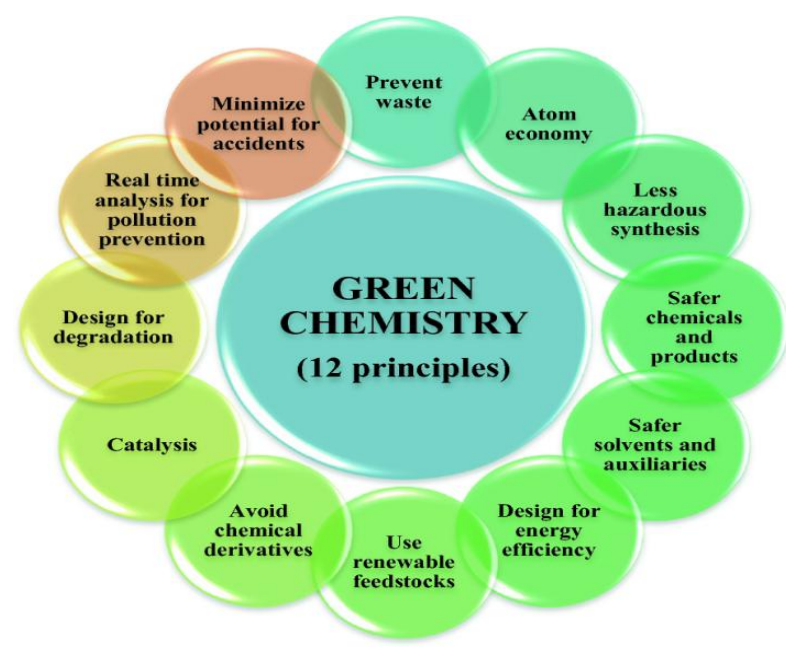

Industrial interest in green chemistry

Many upcoming looking companies are getting and understanding green chemistry, not only to protect or to safety of the environmental background and to create good public relations, but also because it is often beneficial to the bottom line. It is also estimated to cost US industries between $\$ 100$ and $\$ 150$ billion per year to comply with environmental regulations. In addition, cleaning up hazardous waste sites will cost hundreds of billon of dollars. In many companies, the cost of dealing 
with environmental regulation often exceeds there expenditure for research. Bigger companies budget near about $\$ 1$ billion per year for environmental compliance. If company can significantly reduce or decrease this expenditure, then these funds can be spend in more protective areas and result in an improved bottom line. Thus, Green Chemistry (pollution prevention) is not only good for the environment but also for the industry.[8]

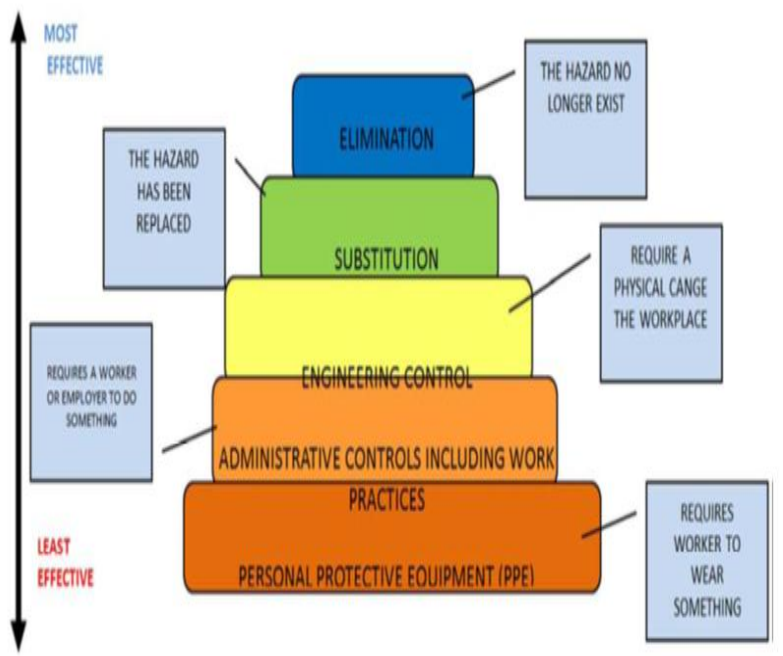

Figure 1: Hirarchy of control of hazards.

\section{Conclusion}

It is interesting to take a position on the event of such a focused biocatalysis-based industry. It is likely that a minimum of another decade will pass before a big biocatalysis-driven company emerges. A very important attribute of such a company will be the ability of management not to be side-tracked by nonissues, examples of which are:

- Toxic compounds: educts, products

- Polar, apolar, mixed-phase biotransformation media

- Reactor systems: batch or continuous

- Product recovery: batch or integrated
- Waste handling

- Geopolitics

- Biosafety regulation

What will matter is the extent to which a biocatalysis company manages to focus on the market, on the development of biocatalysts to address market needs, and on the ability to compare the potential of biocatalysts and chemical alternatives. Finally, it is possible to list some of the properties of that company that is likely to emerge as the premier biocatalysis company in the next decade:

- Understands the chemicals market.

- Biocatalyst and process development: done by organic chemists, chemical engineers, also as molecular biologists.

\section{References}

1. Goyal Anju,Saini Vandana, Arora Sandeep;Green chemistry: a new approach towards science; Discovery Chemistry;2014;1(1);1-15.

2. Ritter, S. K. Green Chemistry. Chem. Eng. News, ;2001: 79 (29), 27-34.

3. Vojvodić, V; Environmental Protection: Green Manufacturing in the Pharmaceutical Industry and Cost Reduction, Kem Ind;2009;58 (1): 32-33,

4. Riđanović, L., Ćatović, F., Riđanović, S.;The Green ChemistryEcological Revolution in the Classroom. 8th Research/Expert Conference with International Participations "QUALITY 2013", Neum, B\&H, June 2008;06 (08);447-452.

5. ANITA K. TAKSANDE, R. D. RAUT, M. D. CHOUDHARY, K. R. DAHAKE;Review Article on Green Chemistry: Challenges and Its Application in Daily Life International Conference on Recent Trends in Engineering Science and Technology (ICRTEST 2017);20017;5(1);504-506.

6. Robert thornton Morrison, Robert Neilson boyd and Saibal Kanti Bhattacharjee.;"organic chemistry" seventh edition pg. no. 1419- 1427.

7. Vesela R Veleva and Berkeley $\mathrm{W}$,; The role of drivers, barriersand opportunities of green chemistry adoption in the major world market;ELSEVIER;Current opinion in green chemistry;2019; 19(1);30-36

8. ALEKASANDRA Kurowaska-Susdorf,Stanislava Talic, Anita lavankovic;Green analytical chemistry:social dimension and teaching; Trends in analytical chemistry;ELSEVIR;2019;11(6);248253. 